\title{
Building Bridges and Breaking Barriers: OER and Active Learning in Mathematics
}

\author{
Ann Gagné \\ Robert Gillespie Academic Skills Centre, \\ Institute for the Study of University Pedagogy, \\ University of Toronto Mississauga \\ Xinli Wang \\ Department of Mathematics \\ University of Manitoba \\ Timothy Yusun \\ Department of Mathematical and \\ Computational Sciences \\ University of Toronto
}

\section{Correspondence:}

Ann Gagné

Robert Gillespie Academic Skills Centre, Institute for the Study of University Pedagogy, University of Toronto Mississauga

Email: ann.gagne at utoronto.ca

\begin{abstract}
This article will discuss how open educational resources and instructional technology are used to support student academic success and continuous faculty pedagogical development, as well as reduce barriers to access at an $\mathrm{R} 1$ university. This article uses case examples from two instructors from a Mathematics and Computational Sciences department who are using open educational resources and instructional technology as part of an inclusive active learning pedagogy. The first case study is from an integral calculus course and the second case study is from a discrete mathematics course. The article highlights the role of the educational developer in providing pedagogical and technological support to the faculty. The support the educational developer provides is framed by an inclusive pedagogy that foregrounds access and accessibility. Future considerations provided in the article highlight the need for connections and collaborations supported through a Teaching and Learning Collaboration with an emphasis on active learning, classroom training, and open educational resources to create more pedagogically comprehensive and inclusive learning environments.
\end{abstract}

Keywords: active learning, open educational resources, barriers, community, teaching and learning 


\section{Introduction}

This collaborative article is an exploration of how open educational resources and technology can be used to support student academic success and continuous faculty pedagogical development. In its presentation and content, the article models the building of bridges and the importance of addressing and reducing pedagogical barriers in the authors' pedagogical theory and praxis. Through two case studies from instructors affiliated with a Mathematics and Computational Sciences department at an R1 university, the authors explore how open educational resources and technology are an integral part of an inclusive active learning pedagogy. The first case study is from an integral calculus course and the second case study is from a discrete mathematics course. We expand on the open educational resources and the active learning strategies used in the courses to discuss how educational developers can provide both pedagogical and instructional tool support for faculty that enhances community building. If the support the educational developer provides is framed by inclusive pedagogy, as demonstrated in this article, there is a foregrounding of access and accessibility that can build bridges between departments and courses as well as address barriers commonly found in courses: barriers that tend to impede student success. By highlighting the connections and collaborations supported through a Teaching and Learning Collaboration community at the R1 university, with emphasis on active learning classrooms and training as well as open educational resources embedded in courses, this article provides an approach to creating a pedagogically comprehensive and inclusive learning environment that is evidence based.

The first case study highlights active learning strategies and open educational resources used in an integral calculus course, where instruction was conducted across interconnected smart classrooms, with a single professor, eight teaching assistants, and over three hundred undergraduate students. This case study demonstrates how to leverage a unique infrastructure so that all classrooms of students are actively engaged as a single learning community, and how to enable students across all classrooms to construct a community knowledge base that serves as a resource for subsequent learning activities. This case study models a bridging of knowledge using active learning patterns that take advantage of the affordances of the synchronous smart classroom. Theoretically, these classrooms are guided by the Knowledge Community and Inquiry (KCl) model (Slotta \& Najafi, 2013), and the case used several open technology tools and environments, including Rain Classroom, GeoGebra, Desmos, and Padlet, to facilitate the active learning activities.

The second case study expands on strategies used in a discrete mathematics course at an R1 university. For the past several years, the method of course delivery for the discrete math course had been a traditional lecture model. In the fall 2019 semester, this discrete math course was taught in an Active Learning Classroom (ALC) in a new building at the R1 university. A flipped classroom method was used to deliver the course: presentations of definitions and basic examples were provided as pre-class material that students review before coming to class, then students would form collaborative teams and engage actively with the material during the scheduled class time through solving problems and working on various activities in the classroom.

The first author, an educational developer at the R1 university, works with faculty, sessional lecturers, postdoctoral fellows, and teaching assistants to find theoretical and practical resources that will best fit the pedagogical goals of the courses they teach, while consistently putting access and accessibility to the forefront. In the first case study, the educational 
developer used the important outcomes from the use of open-educational resources and active learning pedagogy to advocate for the integration of these tools in other courses in the math department, and other courses that have a need for visual interpretations of math, such as geography. This encourages active learning that is supported by evidence-informed pedagogy and educational tool literacy to ensure student access to authentic academic experiences. In the second case study, the educational developer provided support in the form of instructor and teaching assistant training in the active learning classroom as well as consultations for activity ideas, lesson plans, and ways to foster inclusivity and accessibility in this new classroom environment. By prioritizing accessibility, the educational developer or those in similar roles at other institutions (which fall under role titles such as faculty developers, academic developers, and instructional designers) can provide a holistic guiding vision for inclusive pedagogy on campus.

\section{Review of Literature}

Active learning is characterized as a pedagogical approach in which students are involved in activities in the classroom (e.g., writing, problem-solving, peer discussions) other than passive listening and note-taking, where the classroom is used for student skill development instead of instructor-student transmission of information (Bonwell \& Eison, 1991). It has been shown that incorporating elements of active learning in STEM courses leads to better student performance when compared to traditional lecturing (Freeman et al., 2014; Laursen et al., 2014; Lo et al., 2017), even when students may perceive the opposite (Deslauriers et al., 2019). Moreover, there is evidence that active-learning methods reduce racial (Carter et al., 2018) and gender (Laursen et al., 2014) gaps in student performance.

This definition of active learning as "anything that isn't passive learning" is quite expansive and subsumes teaching methods of many different varieties; for instance, collaborative learning, cooperative learning, and problem-based learning can all be characterized as having components of active learning in their respective methodologies (Prince, 2004). The case studies in this paper use the Knowledge Community and Inquiry and flipped classroom methods, and we explicate their characteristics here.

\section{Knowledge Community and Inquiry}

In recent years, a learning-community approach has been developed (Scardamalia \& Bereiter, 1996) in education. Senge (1990) defined learning organizations as "organizations where people continually expand the capacity to produce the results they truly desire, where new and expansive patterns of thinking are nurtured, where collective aspirations are set free, and where people are continually learning how to learn" (p. 3). A learning community, similar to a learning organization, fosters an environment where people can learn to learn together, advancing collective knowledge and supporting the growth of individual knowledge. This learning community approach is applicable to the learning done by students in the R1 university, but also by the community of faculty and instructors that become part of a teaching and learning collaborative.

Guided discovery (Brown, 1994), where the instructor plays the role of facilitator, guiding the student's learning journey, is effective when student interactions and inquiry processes are assessed in a timely fashion and the instructor has an awareness of when to intervene. The instructor plays a critical role in this model, as they must guide the discovery process into forms of inquiry that may not be otherwise reached.

Open/Technology in Education, Society, and Scholarship Association Journal: 2021, Vol. 1(1) 1-20 
In order to bridge the perspectives of knowledge building (Scardamalia, 2002) and foster a community of learners (Brown, 1997), a pedagogical model known as Knowledge Community and Inquiry (KCl; Slotta \& Najafi, 2013) was designed. The $\mathrm{KCl}$ model emphasizes community epistemology and knowledge construction, and places importance on the designed sequence of student's activities. In this model, the learner community comes together and collectively constructs a knowledge base. The learning outcomes are assessed constantly and are aligned with learning goals. The teacher's role includes guiding the flow or sequence of activities, assessing student's progress, and giving feedback. $\mathrm{KCl}$ always starts from assessable learning outcomes with collaborative and scaffolded inquiry activities producing these outcomes.

\section{The Flipped Classroom Model}

The flipped classroom is an active learning approach where students are introduced to basic definitions and examples in pre-class material (usually in the form of videos or readings), and inclass time is used to engage with material more meaningfully through formative activities such as group problem-solving, think-pair-share, and the use of clickers (Jungić et al., 2015; Love et al., 2014). This strategy is motivated by the idea that bringing the more difficult parts of the course inside the classroom where the instructor is available for assistance will lead to better student learning, as opposed to covering foundational material in lectures and letting students struggle with higher-level concepts on their own (Love et al., 2014).

A more recent meta-analysis of comparative studies on flipped classrooms found a "statistically significant effect size in favour of the flipped classroom instructional strategy" (Cheng et al., 2019 , p. 793), though we note that there are also studies that report neutral effects on student learning (e.g., Guerrero et al., 2015; Yong et al., 2015). Another study (Zack et al., 2015) determined that preferences of students in a flipped finite mathematics course shifted away from the flipped model in favour of the traditional model, but also

when asked what was most beneficial about the videos, many students highlighted that they could easily stop, rewind, and/or pause the videos while watching them and taking notes. Students also frequently mentioned the benefit of being able to go back later to reference the videos when studying for an exam. (p. 806)

Cheng et al. (2019) in their meta-analysis of flipped classroom studies, saw a general lack of detail about their implementation in the instructor's courses, specifically concerning pedagogies of learning and instructional strategies. This suggests the need for a more robust Scholarship of Teaching and Learning (SoTL) framework in flipped classroom use and theory in higher education.

Traditional lecture halls with a fixed podium in front, and immovable tables or seats, which may be less open to flipped classroom activities, are remnants of attempts to emulate the efficiency of mass factory production in education (Bransford et al., 2000; Park and Choi, 2014). With recent advancements in technology, many institutions of higher education are adapting their educational spaces to better accommodate active-learning pedagogies (Johnson et al., 2019; Park and Choi, 2014), including the R1 university where the authors work.

\section{Active Learning and Open Educational Resources}

Open educational resources (OER) are also increasingly part of active learning in mathematics. OER is a term that was first coined at a UNESCO forum on open courseware in 2002 and refer to "teaching, learning and research materials in any medium-digital or otherwise - that reside 
in the public domain or have been released under an open license that permits no-cost access, use, adaptation and redistribution by others with no or limited restrictions" (UNESCO, 2019). Ahn and Edwin (2018) suggested an open source platform to increase the social constructivist pedagogical frame for teaching mathematics, and this use of open source e-learning tools can also help support student success (Akugizibwe \& Ahn, 2020). Not every department or institution is ready to adopt these open educational resources however, because as Masterman (2016) addressed, the challenges of bringing Open Educational Resource practices to research intensive universities is particularly difficult. Contact North (n.d.) created a resource to help dispel the myths about OERs by focusing on the facts about OER use. Similar to work by Jung at el. (2017) on open textbook adoption, Masterman (2016) showed the tension with a presentation of quality in relation to research models at R1 universities. The reinforcement of the role of inclusive pedagogy and student accessibility, alongside rigorous scholarly approaches to open resource creation are often the best incentive for faculty adoption in the face of concerns over quality. Recent pivoting to a remote delivery due to COVID-19 has yet to determine how much an increase in OER use will occur in research-intensive universities, but the ease of access, quality of the product, and ability to be made context specific, is important in a distance-learning environment. Chiorescu (2017) echoed the financial savings for students, especially in relation to mathematics textbooks, and thus the ability to support student success.

\section{Educational Developers and Similar Roles as Supporting Faculty}

The educational developer role may be named differently at many institutions in terms of scope and administrative placement. For example, much of what the educational developer does in their role can overlap with instructional designers and instructional technologists. The name of the role may also differ based on geographical location, where in the United States educational developers are called faculty developers, and in the UK they are called academic developers. From the development of faculty support roles, there has often been overlap in terms of scope of the role with technology services and with career training (Wilcox, 1998). Studies indicate that one of the roles of educational developers is to show the connection between theory and praxis and this is especially true in STEM fields in terms of pedagogy. Mulnix (2016) showed that discipline-based educational research (DBER) has importance for both faculty and student success: "an understanding of the learning principles that are the foundation for alternative teaching and learning strategies can help faculty members develop the ability to transfer knowledge to their own circumstances" (p. 7) and as such, an educational developer can provide access to these DBER resources and supplement how these resources are applied to the instructor's particular field. This is also supported by Kennedy's substantial study that suggested the need to align professional development models and research models (2016).

This modeling is an important part of inclusive pedagogy and bridging relationships in higher education. Jenkins (1996) argued that educational developer expertise and faculty's subject matter knowledge work together to create success for students and ultimately allow for professional development in the instructor's career. Jenkins outlined the many intersections of faculty and educational developer roles including SoTL research and training of teaching assistants.

Content knowledge as well as pedagogical knowledge is of equal importance for Teaching Assistants (TAs) who are starting their academic career and need both of these knowledge points as foundation. Judson and Leingang's (2016) study demonstrated the importance of both content knowledge as well as pedagogical knowledge for TAs. Thus, TAs need to have the

Open/Technology in Education, Society, and Scholarship Association Journal: 2021, Vol. 1(1) 1-20 
support of a teaching community and educational developers as well along with their departmental community. Top et al. (2018), also echoed the importance of relating STEM content to the assistant's pedagogical training if it is to be effective and successful for student support.

\section{Critical Pedagogy, Reflection, and Faculty Peer Dialogue}

Bond (2016) suggested the use of online professional learning communities can support math pedagogues with their praxis and identify gaps in pedagogical strategy and instructional technology use. This colleague community dialogue can be taken offline as well (GarcíaMartinez et al., 2018) which also underscores how leadership in mathematical departments and institutions is integral to supporting pedagogical development for instructors and in turn helps foster student success. Work by Tinnell et al. (2019) underscored the importance of faculty peer dialogue, especially to support pedagogical change and innovation in STEM programs, where a community of like-minded scholars that are part of a community of practice or a pedagogical study group can expand institutional pedagogical and curricular quality and mental wellness in the workplace which we will return to in our discussion.

\section{Design and Implementation of Pedagogical Practice Case Studies}

\section{Case 1: Calculus and Learning Community}

\section{Knowledge Community and Inquiry}

In the fall semester of 2019 , the second author led the development of 27 lesson plans spanning 16 weeks using a learning community pedagogy for a Calculus II course. This course was offered in a public university in China, and taught by one professor, facilitated by a group of eight TAs. Students occupied seven connected smart classrooms while attending lectures. Each classroom has around 35 students sitting in groups, and was equipped with cameras, WiFi, and overhead projectors. The instructor's lecture was recorded and live streamed to all classrooms. A communication platform called Rain Classroom was used to host students' discussions and allow groups to share their work. Rain Classroom was specially designed to be used in a blended learning environment and it allows students to interact with their teachers and peers in class and out of class using their smartphones. It also provides real-time and personalized analysis of students' class performance.

The professor usually stayed in one of these classrooms while teaching, and students in other classrooms could watch the professor via live streaming. When designing in-class activities, the main goal was to foster a strong culture of learning community among students, and encourage student interactions when they were working through given assignments in small groups. These activities can be categorized into one of the following four patterns; a table of examples from each pattern can be found in Appendix A.

- Peer Instruction (PI): The instructor would post a clicker question to the community and invited students to share their answers and reasons before showing the response distributions. Once students had the chance to hear from peers, they were asked to vote again on the same question for the second round, then the instructor would share both responses with the whole community. By doing this, we could leverage peer instruction and see to what extent it impacted the community learning.

- Community Supported Worksheet (CSW): Students received two worksheets as part of this activity. First, was a basic worksheet provided with the assumption that students would have the skills and knowledge to solve all the questions on it. This worksheet was 
then followed by a more challenging worksheet for those who are at a different knowledge and skill level in a differentiated learning model. Students who were able to complete the first worksheet were then invited to add hints or support for their peers.

- Community Problem Creation (CPC): All students were invited to create clicker questions after class, and they would cast votes for the best ones. The whole community would then work together in class on the popular ones and these questions would be used by the instructor later in the course. This activity gives students the opportunity to become course co-creators and reflect on their learning journey, in a social constructivist model.

- Participatory Problems or Patterns (PPP): In this activity, classes worked together to embody a mathematical concept. Usually there are multiple steps in one activity, and the solutions to early steps are necessary for students to solve the subsequent ones. All groups must work closely with each other in order to find final solutions. Padlet was used for students to share ideas with each other, specifically outlining what they already know and the gaps they identified in their knowledge and skill to solve the whole activity.

\section{Student Epistemological Beliefs}

In order to run these activities smoothly, TAs and the instructor must receive proper training ahead of time in order to facilitate student discussions and make sure they are proceeding effectively. The skill sets required to facilitate this sort of instructional framework are quite different from those that are needed for traditional face-to-face lecturing. The second author found that students tend to have a positive attitude about the value of peers and teaching assistants as sources of knowledge after going through activities using this framework. We believe community knowledge is a powerful tool that can be used to improve students' learning experience, to bridge knowledge gaps, and to enhance their ability to communicate mathematical ideas more effectively. This case study is grounded in an inclusive framework where the differentiated learning directly addresses knowledge barriers.

Epistemological beliefs are individuals' conceptions about the nature of knowledge and the nature or process of knowing and are considered important for the learning process (Kampa et al., 2016). Students in this case study were surveyed via questionnaires that were distributed by the teaching assistants along with consent forms. The survey (see Appendix B) focused on their epistemological beliefs at the beginning and end of the semester. A total of 308 students were invited to participate and $220(71.42 \%)$ participants provided both pre- and post-course responses. Of this group, 49 identified as male and 171 identified as female. The course year demographic was 206 in their first year of studies, 12 in their second year of studies, and two were in their third year of studies. Significant gains $(p<0.001)$ on all four major categories were observed: personal relevance and learning preferences $(M=3.24, S D=0.26, t=-6.82)$, learning from peers $(M=3.09, S D=0.41, t=-5.48)$, teaching and sources of knowledge $(\mathrm{M}=$ 3.38, $S D=0.28, t=-6.95)$, and engagement $(M=3.32, S D=0.48, t=-6.03)$. More details about the implementation of this framework and effects on student engagement can be found in Li et al. (2020).

There are limitations to this case study; specifically, the need for more data on how students work together in a group. The structure of this particular case made it difficult to capture what makes group collaboration successful and more in-depth observation is needed in order to answer this question. 


\section{PI, Active Learning Pedagogy, and Instructional Technology}

In terms of the support provided by the educational developer for this case work, though this study was conducted in classrooms in China, this model showed a lot of promise for use at the authors' R1 university in Canada, especially in relation to Active Learning Classrooms and support needed for the continued use of open educational tools and resources. Many instructors at the R1 university have already been using a Peer Instruction (PI) model, developed by Mazur (1997), to support active learning in their courses, particularly in the chemistry and physical sciences department. The main purpose of $\mathrm{PI}$ is to foster conceptual understanding. Mazur's work on $\mathrm{PI}$ emphasizes an active learning model where students are given time to reflect, record, and then convince and revise where necessary. As Vickrey et al. (2015) suggested, there also needs to be attention placed on race and gender, as there seems to be a correlation in the use of PI to these data demographics. Ultimately, in terms of using PI as part of pedagogy that enhances student success, Zhang and Henderson (2016) demonstrated that PI has the ability to increase recall and comprehension, which makes it an excellent model applicable across many disciplines, but in particular for use in STEM.

In addition, there has been success using the instructional technology that was used in this case to support the types of differentiated learning. By setting up a practice of having basic, mid, and higher skill exercise questions, coupled with the use of instructor curated resources and tools (for example, etextbooks, discipline specific open instructional technology such as GeoGebra), students can work together through the levels of difficulty in order to attain mastery of a concept. Dosch and Zidon (2014) performed a study that demonstrated that students in differentiated learning environments increased student performance which is echoed in the case study above.

\section{Case 2: Discrete Mathematics and the Active Learning Classroom}

\section{Active Learning Classrooms at the R1 University}

In September 2018, the R1 university unofficially opened the doors to a new building on campus, which houses a number of active learning classrooms (ALCs). Early planning for this new space saw a subset of project committee members visiting ALC implementations in a number of Canadian and US universities in order to support the architectural design, technological needs, and pedagogical requirements.

The new ALCs at the R1 institution are designed for a collaborative classroom environment, with flat floors and round tables (or "pods") around the perimeter. Each pod has six rolling chairs, its own microphone that broadcasts through speakers in the ceiling to the rest of the room, whiteboard screens, and a projector with device hookup capabilities that include wireless and HDMI ability. A teaching station is in the center of the room, with a computer and monitors, a document camera, microphones, and a room control system where settings for video/audio sources, lighting, and volume can be set. This also allows the instructor to set content to be displayed on any individual pod and on ceiling-mounted monitors around the room, switching between instructional material and student group outputs. Figure 1 below provides an example of this room.

Faculty delivering courses in these technology-enhanced ALCs are required to attend a training session with educational developers. This campus at the time had one educational developer responsible for this training along with support from the library's instructional technologies team. During the training session provided by the educational developer, the functionalities of the ALC are demonstrated and linked to examples of pedagogical approaches that work well using each 
tool and affordance, bridging the gaps between pedagogy and technology. Interactive whiteboards used for the pod display screens mean that students can use digital markers to annotate displayed content but-based on the third author's experience - it is not as responsive and easy to use as using physical markers to annotate.

\section{Flipping the Discrete Mathematics Classroom}

The Introduction to Discrete Mathematics course at the R1 university is a second-year course taken by students in the mathematics programs; topics covered include sets and functions, counting principles, graph theory, and elementary number theory. Emphasis is placed on abstraction and proof writing; it is typically seen as a continuation of the first-year introduction to proofs course. The third author taught this course in the ALC in the Fall 2019 term, with a class size of 90 students. Prior to this, the course was delivered in a conventional lecture classroom using a traditional lecture format. Discrete mathematics is well-suited for the exploratory and collaborative style the ALC affords: for instance, many problems in combinatorics have several (sometimes drastically different) solutions that students are able to discover and discuss within their groups. Being able to draw on their own whiteboards allows each group to explore the mathematics themselves, centering learning on the students rather than the instructor.

\section{Figure 1}

\section{Active Learning Classroom in R1 University}

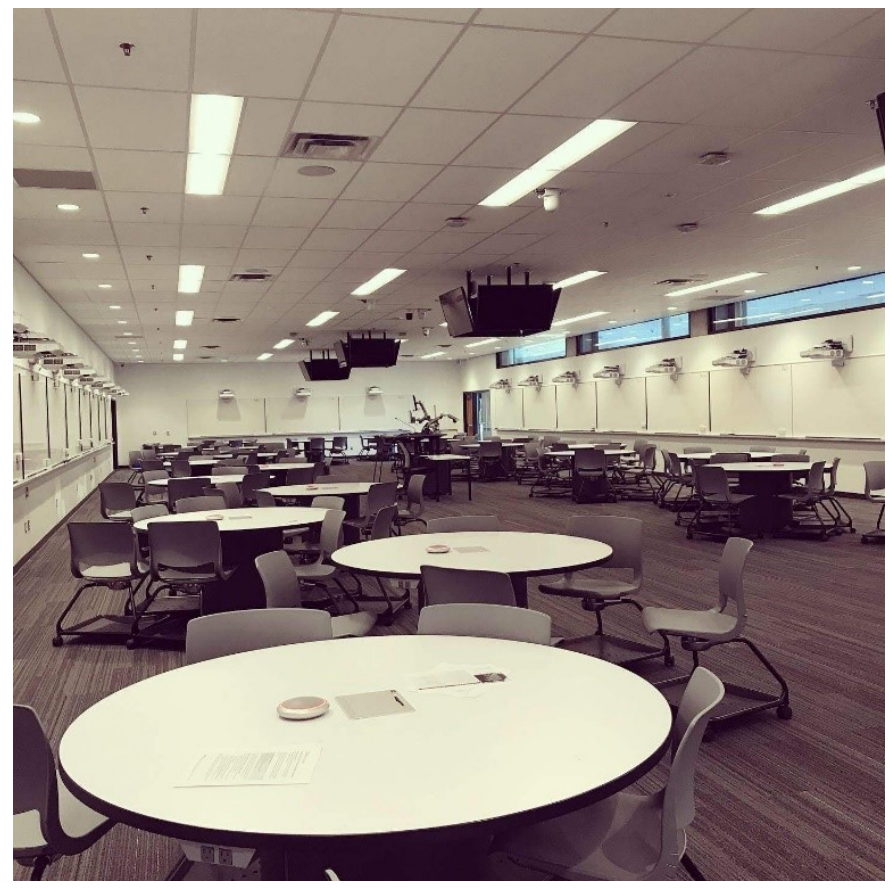

Note. Photo by Ann Gagné.

Notes were also written for this course and posted on the learning management system (Canvas), giving students a cost-effective and accessible reference as new copies of the previous textbook cost about $\$ 150 \mathrm{CDN}$. Each chapter of the course notes ends with a number of practice exercises. Additional exercises were also interspersed among definitions, examples, and theorems to give the notes an active learning component as well. Students were assigned weekly readings from the course notes and were asked to complete a pre-class quiz about 
basic definitions and examples before coming to class. These quizzes made up a small component of their grade and were mostly multiple-choice or fill-in-the-blank type questions. The instructor would then review the quiz results to prepare for class and address any identified misconceptions in class after a brief review of topics. These quizzes allowed the instructor to address any barriers to knowledge and to bridge those gaps through specific activities and questions.

The majority of in-class time was used for collaborative problem-solving. Students self-formed into groups when entering the classroom and were given daily worksheets. They were encouraged to be physically active: to stand and brainstorm their solutions to the problems on the whiteboards instead of sitting at their pods. This way, the instructor and TA were able to quickly check on student work from afar and give timelier formative feedback.

At the end of the semester, students completed an exit survey about their experiences with the course. The survey was not anonymous and contained three open-ended questions: (a) what they liked about the ALC and active learning delivery, (b) what they disliked about the ALC and active learning delivery, and (c) a space for them to enter any additional comments.

Many of them found the classes engaging ("less sitting and being talked at") and liked learning in groups ("everyone has different ideas"). They enjoyed being able to receive immediate feedback on their work, which encouraged them to participate and attempt the given problems, though some reported longer wait times for help, since there was only one additional TA to help out in class. The third author also notes that the ALC setup made it easier to form a community of learning. Students reported being able to make connections in this classroom and continuing these friendships even after the course. Finally, students were less enthused about the technology in the classroom; pod microphones turned on randomly, and the projectors and interactive whiteboard did not always work properly, which suggests that the architecture and the activities that were part of the pedagogy of the course often take priority over instructional technology affordances, especially if the students are not well-trained or versed in using the technology.

\section{Educational Developer Support to Active Learning and Accessibility Considerations}

There has sadly not been enough work done on accessibility and the design of active learning classrooms as a physical space as demonstrated by Grier-Reed \& Williams-Wengerd (2018), so there are definitely research possibilities on where active-learning spaces, instructional technology, and pedagogy intersect. Buchenot and Roman (2019) have expanded the understanding of what we deem as the affordances of technology. Their case, which moved through different active learning desk arrangements, demonstrates a use case for each type of arrangement in an accessible manner that supports Universal Design for Learning (UDL) principles. UDL principles necessarily intersect with ALC use and ALC assessment and activity design for the ALCs allow for a choice model of pedagogy that supports inclusion. UDL thus becomes a way to bridge the gaps in understanding access.

As mentioned above, support is provided to both instructors and teaching assistants on the pedagogical affordance of the ALC. One of the topics that was highlighted is how to ensure accessibility in course activity and assessment design in the active learning classrooms to address inadvertent physical barriers in the ALC space. Activities such as collaborating on whiteboards, for example, can be made more inclusive and accessible with digital whiteboard 
apps or by accessing the whiteboard through their own devices which means students do not physically need to be in front of the board to participate. All of the ALCs at the R1 university are equipped with "bring your own device" wireless connection through the AirMedia app that students can download onto their device.

Another way of ensuring engagement and reducing barriers occurred in the original consultation on the ALC design. The room is designed with Accessibility for Ontarians with Disability Act $(A O D A)$ requirements in mind so students who are wheelchair users can also use the whiteboard by approaching the board. This adds choice to the engagement opportunities and is aligned to Universal Design for Learning principles. The first author, who is the educational developer, advocates and supports ongoing discussions with instructors about accessibility and inclusivity in the ALCs and in the assessment pedagogy and assessment design used in the rooms. There are many ways to make activities more inclusive in these ALC spaces using open educational resources and the free instructional technology apps that can be projected to all of the screens in the ALC classroom. Other barrier reduction mechanisms that are part of ALC training are asking instructors to be aware of both sound and light barriers in the rooms. A best practice that has been suggested for instructor implementation is to have the lights in the room at medium strength to reduce glare in light pollution in the classrooms when technology is in use. This is in line with the City of Mississauga Facility Accessibility Design Standard, Section 4.4.13 which states, "Light sources and fixtures shall be selected to minimize direct glare or indirect glare on nearby reflective surfaces" and "Lighting in meeting rooms [emphasis in original] and assembly areas shall be evenly distributed, and shall be capable of being adjusted (e.g., dimmers)" (City of Mississauga, 2015, para. 13, 22). Another strategy is to ensure all the microphones are originally turned off so that there is no overwhelming sound pollution as a barrier when students are in the classroom and particularly when they are working as groups.

\section{Recommendations for Future Practice}

We propose directions for future practice and areas for continued research that arise from these case studies, as well as from experience and engagement with active learning classrooms. They are recommendations informed by research on active learning classroom practice and how to make these classrooms spaces that are more accessible, coupled with using open educational resources as a way to reduce barriers to math education.

There is a large body of evidence supporting active learning and what supports need to look like in face-to-face delivery. Now in a remote teaching and learning environment due to COVID-19, more research on active learning online (beyond the use of classroom assessment techniques (CATS; Angelo and Cross, 1993) needs to be done. There must be reinforcement for the ample support provided to instructors who would like to adopt active learning techniques in their courses regardless of delivery modality. These case studies and research have demonstrated that for active learning to be effective it needs to be done well and supported by contextual practices for each course. There is no singular set of best practices for active learning that apply to all courses in a discipline, but there are certainly good practices that support access and accessibility, as outlined above. Building bridges for students by asking them for their feedback, early and often, as well as building bridges amongst faculty through professional development and training opportunities is one way to embed more active learning (including the use of OERs) in course pedagogy. 
A strategy that is useful to increase access to math courses in a more comprehensive manner is to reflect on pedagogical practices and perform accessibility audits to reduce barriers in the class for students. This includes race, class, disability, gender expression, and sexual orientation, as well as intersections of these positionalities. This also includes the need to reduce barriers for faculty who want to implement active learning or other strategies in the classroom, from a curricular and access to technology and training standpoint. These barriers can be even more pronounced for precarious faculty, who may not have the time to develop materials themselves, or access to the resources to support their curricular and pedagogical development. It is important to remember that creating materials takes time and needs support, and these supports can appear in many different ways, for example

- Creating videos, guided readings, and/or activities for pre-class/in-class/post-class settings that can be shared by faculty and readily scaffolded to different aspects of a course.

- If in a technologically-advanced room, providing training on how to use the room, and how to plan classroom activities that take advantage of the classroom affordances. This includes highlighting which features would best support certain types of activities.

- OER support and advocacy to reduce cost of access to the course for students. OERs are often criticized for being less rigorous, but remote teaching and learning has demonstrated how OER can and should have a valuable role in our courses. For example, the third author developed an online version of their course notes using PreTeXt (Beezer et al., 2019) that is more accessible (compatible with screen readers and smaller devices) and is now offering both this online version and an offline PDF version for students.

- Support for faculty to consider what makes group work effective or how group activities can be structured so that they support active learning and inclusion for all students.

These possible practical recommendations also lead to the need for future research on active learning spaces and comprehensive accessible design, as well as student attitudes towards OER as compared to traditional hard copy purchased textbooks from academic publishers.

\section{Conclusion and Next Steps}

Both of the case studies described here are demonstrations of how separate practices are informed and supported by the educational developer's work and the teaching and learning community on campus. Scholarship of Teaching and Learning (SoTL) work done by faculty members at the R1 university, even prior to coming to our institution, are entry points for a larger dialogue and advocacy around the need to break down barriers to education through an inclusive and accessible pedagogy. As the case studies demonstrate, the use of OERs and ALCs has been an effective way to engage students in learning and to foster a barrier-reduced environment with multiple means of interaction and multimodal possibilities. The Teaching and Learning Collaboration (TLC) has traditionally been the hub for discussion about active learning pedagogical practices and a place where faculty from all disciplines can meet to discuss pedagogical issues and to be in community. The TLC provides a yearly ALC showcase where faculty, instructors, and graduate students provide best practice resources for future use of the ALC from a pedagogical and instructional technology model. Faculty and instructors also give a series of lightning talks over the span of the school year where they outline instructional technology and OER pedagogical use in their courses. 
In a response to COVID-19, this collaboration has also provided webinars to support the transition to remote learning. The webinars are based and model an active-learning and inclusive pedagogy. The webinars model inclusivity and barrier reduction by providing slides and material ahead of time, live captioning the webinar in real time, and a recording of the webinar with accessible transcripts following the webinar. Recommendations for instructional technology use for the faculty is guided by access principles where open tools and resources that are both AODA and WCAG 2.1 compliant are suggested. Faculty, in turn, used these practices when they designed their courses.

A community of learning focused on barrier reduction and bridge building was also provided, before the pandemic, through a monthly lunch series, where faculty and instructors discuss successes and issues in the courses they are teaching. These connection opportunities have now transitioned to an online delivery during social distancing due to the pandemic. These opportunities to communicate support faculty and instructor professional development and strengthens community around teaching and learning. This community building and intersection of the technological and sociological of instructional technology is also emphasized in the biyearly newsletter where successes in the form of grants secured, conference papers given, and "it worked for me" type articles are written by faculty and instructors to inspire future possibilities for pedagogy and instructional technology. The important theme here is that community building is integral to barrier reduction and bridge building, and this requires a strong awareness and visibility of teaching and learning practices and theory on campus. The more visible open educational resources and active learning classrooms that use instructional technology are to other faculty, the more likely others are to use these techniques and innovate new inspiring accessible practices grounded in evidence-based approaches that will lead to student success.

\section{Author's Contributions}

$\mathrm{XW}$ was investigator and main author for Case 1 and the $\mathrm{KCl}$ subsections in the Review of Literature; TY was the investigator and author for Case 2, and the active learning and flipped learning sections in the Review of Literature. AG was primary author for the introduction, the second half of the Review of Literature, and the subsections under both cases that discuss continued educational developer support for the projects.

\section{Open Researcher and Contributor Identifier (ORCID)}

Ann Gagné (iD https://orcid.org/0000-0002-3069-8783

Xinli Wang iD https://orcid.org/0000-0003-1717-9062

Timothy Yusun iD https://orcid.org/0000-0003-0733-9659

\section{Ethics Statement}

Ethical approval was obtained for the survey instrument mentioned here under RIS Protocol number 38329 and application name "Active Learning Designs for Smart Classrooms in China."

\section{Conflict of Interest}

The authors do not declare any conflict of interest.

\section{Data Availability Statement}

The data listed in this article is not publically available as the case study data is a result of an international collaboration. Queries about the case study data from this collaboration may be directed to Xinli Wang. 


\section{References}

Ahn, J. Y., \& Edwin, A. (2018). An e-learning model for teaching mathematics on an open source learning platform. The International Review of Research in Open and Distributed Learning, 19(5). https://doi.org/10.19173/irrodl.v19i5.3733

Akugizibwe, E., \& Ahn, J. Y. (2020). Perspectives for effective integration of e-learning tools in university mathematics instruction for developing countries. Education and Information Technologies, 25(2), 889-903. https://link.springer.com/article/10.1007\%2Fs10639-01909995-Z

Angelo, T. A., \& Cross, K. P. (1993). Classroom assessment techniques: A handbook for college teachers. Jossey-Bass Publishers.

Beezer, R. A., Farmer, D., Jordan, A., \& Keller, M. T. (2019). The PreTeXt Guide. https://pretextbook.org/doc/guide/html/guide-toc.html

Bond, V. (2016). Using online professional learning communities to encourage dialogue in university/college mathematics. International Journal for Technology in Mathematics Education, 23(2), 87-90.

https://go.gale.com/ps/anonymous?id=GALE|A459075813\&sid=googleScholar\&v=2.1\&it=r\& linkaccess=fulltext\&issn=17442710\&p=AONE\&sw $=w$

Bonwell, C. C., \& Eison, J. A. (1991). Active learning: Creating excitement in the classroom. 1991 ASHE-ERIC Higher Education Reports. ERIC Clearinghouse on Higher Education, The George Washington University, Washington, DC. https://eric.ed.gov/?id=ED336049

Bransford, J., Brown, A., \& Cocking, R. (Eds.). (2000). How people learn: Brain, mind, experience, and school: Expanded edition. National Academies Press.

Brown, A. L. (1994). The advancement of learning. Educational Researcher, 23(8), 4-12. https://doi.org/10.3102/0013189X023008004

Brown, A. L. (1997). Transforming schools into communities of thinking and learning about serious matters. American Psychologist, 52(4), 399-413. https://doi.org/10.1037/0003066X.52.4.399

Buchenot, A., \& Roman, T. A. (2019). Reframing writing instruction in physical learning environments: Making connections between digital and nondigital technologies. Journal of Teaching and Learning with Technology, 8(1), 87-98. https://doi.org/10.14434/jotlt.v8i1.26793

Carter, C. L., Carter, R. L., \& Foss, A. H. (2018). The flipped classroom in a terminal college mathematics course for liberal arts students. AERA Open, 4(1). https://doi.org/10.1177/2332858418759266

Cheng, L., Ritzhaupt, A. D., \& Antonenko, P. (2019). Effects of the flipped classroom instructional strategy on students' learning outcomes: A meta-analysis. Educational Technology Research and Development, 67(4), 793-824. https://doi.org/10.1007/s11423018-9633-7

Chiorescu, M. (2017). Exploring open educational resources for college algebra. International Review of Research in Open and Distributed Learning, 18(4), 50-59. https://eric.ed.gov/?id=EJ1146209

City of Mississauga. (2015). Facility accessibility design standards. http://www7.mississauga.ca/Departments/Marketing/Websites/Accessibility/Mississauga F ADS.html\#a4.4.13

Contact North. (n.d.). Ten facts about Open Educational Resources (OER). https://teachonline.ca/sites/default/files/toolstrends/downloads/ten facts aboutopen educational resources.pdf

Deslauriers, L., McCarty, L. S., Miller, K., Callaghan, K., \& Kestin, G. (2019). Measuring actual learning versus feeling of learning in response to being actively engaged in the classroom. 
Proceedings of the National Academy of Sciences, 116(39), 19251-19257.

https://doi.org/10.1073/pnas.1821936116

Dosch, M., \& Zidon, M. (2014). The course fit us": Differentiated instruction in the college classroom. International Journal of Teaching and Learning in Higher Education, 26(3), 343357. http://www.isetl.org/ijtlhe/

Freeman, S., Eddy, S. L., McDonough, M., Smith, M. K., Okoroafor, N., Jordt, H., \& Wenderoth, M. P. (2014). Active learning increases student performance in science, engineering, and mathematics. Proceedings of the National Academy of Sciences, 111(23), 8410-8415. https://doi.org/10.1073/pnas.1319030111

García-Martínez, I., Ubago-Jiménez, J. L., López-Burgos, J., \& Tadeu, P. (2018). The pedagogical leadership of the mathematics faculty: A systematic review. Education Sciences, 8. https://www.mdpi.com/2227-7102/8/4/217

Grier-Reed, T., \& Williams-Wengerd, A. (2018). Integrating universal design, culturally sustaining practices, and constructivism to advance inclusive pedagogy in the undergraduate classroom. Education Sciences, 8(4), 167. https://www.mdpi.com/22277102/8/4/167

Guerrero, S., Beal, M., Lamb, C., Sonderegger, D., \& Baumgartel, D. (2015). Flipping undergraduate finite mathematics: Findings and implications. PRIMUS, 25(9-10), 814-832. https://doi.org/10.1080/10511970.2015.1046003

Jenkins, A. (1996). Discipline-based educational development. International Journal for Academic Development, 1(1), 50-62. https://doi.org/10.1080/10511970.2015.1046003

Johnson, A. W., Blackburn, M. W., Su, M. P., \& Finelli, C. J. (2019). How a flexible classroom affords active learning in electrical engineering. IEEE Transactions on Education, 62(2), 91-98. https://ieeexplore.ieee.org/document/8470966

Judson, T. W., \& Leingang, M. (2016). The development of pedagogical content knowledge in first-year graduate teaching assistants. Journal of STEM Education: Innovations \& Research, 17(1), 37-43. https://www.jstem.org/jstem/index.php/JSTEM/article/view/1683

Jung, E., Bauer, C., \& Heaps, A. (2017). Higher education faculty perceptions of open textbook adoption. International Review of Research in Open and Distributed Learning, 18(4), 123141. http://www.irrodl.org/index.php/irrodl/article/view/3120

Jungić, V., Kaur, H., Mulholland, J., \& Xin, C. (2015). On flipping the classroom in large first year calculus courses. International Journal of Mathematical Education in Science and Technology, 46(4), 508-520. https://doi.org/10.1080/0020739X.2014.990529

Kampa, N., Neumann, I., Heitmann, P., \& Kremer, K. (2016). Epistemological beliefs in science-A person-centered approach to investigate high school students' profiles. Contemporary Educational Psychology, 46, 81-93. https://doi.org/10.1016/j.cedpsych.2016.04.007

Kennedy, M. M. (2016). How does professional development improve teaching? Review of Educational Research, 86(4), 945-980. https://doi.org/10.3102/0034654315626800

Laursen, S., Hassi, M.-L., Kogan, M., \& Weston, T. (2014). Benefits for women and men of inquiry-based learning in college mathematics: A multi-institution study. Journal for Research in Mathematics Education, 45, 406-418. https://doi.org/10.5951/jresematheduc.45.4.0406

Li, Y., Dai, J., Wang, X., \& Slotta, J. (2020). Active learning designs for Calculus II: A learning community approach for interconnected smart classrooms. International Journal of Smart Technology and Learning, 2(1), 66-87. https://doi.org/10.1504/IJSMARTTL.2020.109504

Lo, C. K., Hew, K. F., \& Chen, G. (2017). Toward a set of design principles for mathematics flipped classrooms: A synthesis of research in mathematics education. Educational Research Review, 22, 50-73. https://doi.org/10.1016/j.edurev.2017.08.002 
Love, B., Hodge, A., Grandgenett, N., \& Swift, A. W. (2014). Student learning and perceptions in a flipped linear algebra course. International Journal of Mathematical Education in Science and Technology, 45(3), 317-324. https://doi.org/10.1016/j.edurev.2017.08.002

Masterman, E. (2016). Bringing open educational practice to a research-intensive university: Prospects and challenges. Electronic Journal of E-Learning, 14(1), 31-43. https://files.eric.ed.gov/fulltext/EJ1099364.pdf

Mazur, E. (1997). Peer instruction: A user's manual. Prentice Hall.

Mulnix, A. B. (2016). STEM faculty as learners in pedagogical reform and the role of research articles as professional development opportunities. CBE Life Sciences Education, 15(4). https://doi.org/10.1187/cbe.15-12-0251

Park, E. L., \& Choi, B. K. (2014). Transformation of classroom spaces: Traditional versus active learning classroom in colleges. Higher Education, 68(5), 749-771. https://doi.org/10.1007/s10734-014-9742-0

Prince, M. (2004). Does active learning work? A review of the research. Journal of Engineering Education, 93(3), 223-231. https://doi.org/10.1002/j.2168-9830.2004.tb00809.x

Scardamalia, M. (2002). Collective cognitive responsibility for the advancement of knowledge. In B. Smith (Ed.), Liberal education in a knowledge society (pp. 67-98). Open Court.

Scardamalia, M., \& Bereiter, C. (1996). Student communities for the advancement of knowledge. Communications of the ACM, 39(4), 36-37. https://doi.org/10.1145/227210.227220

Senge, P.M. (1990). The fifth discipline: the art and practice of the learning organization ( $1^{\text {st }}$ ed.). Doubleday/Currency.

Slotta, J. D., \& Najafi, H. (2013). Supporting collaborative knowledge construction with Web 2.0 technologies. In C. Mouza \& N. Lavigne (Eds.), Emerging technologies for the classroom: A learning sciences perspective (pp. 93-112). Springer. https://doi.org/10.1007/978-1-46144696-5 7

Tinnell, T. L., Ralston, P. A. S., Tretter, T. R., \& Mills, M. E. (2019). Sustaining pedagogical change via faculty learning community. International Journal of STEM Education, 6(1), 26. https://doi.org/10.1186/s40594-019-0180-5

Top, L. M., Schoonraad, S. A., \& Otero, V. K. (2018). Development of pedagogical knowledge among learning assistants. International Journal of STEM Education, 5(1). https://doi.org/10.1186/s40594-017-0097-9

UNESCO. (2019). Open Educational Resources (OER). https://en.unesco.org/themes/buildingknowledge-societies/oer

Vickrey, T., Rosploch, K., Rahmanian, R., Pilarz, M., \& Stains, M. (2015). Research-based implementation of peer instruction: A literature review. CBE-Life Sciences Education, 14(1). https://doi.org/10.1187/cbe.14-11-0198

Wilcox, S. (1998). The role of the educational developer in the improvement of university teaching. Canadian Journal of Higher Education, 28(1), 77-103. https://journals.sfu.ca/cjhe/index.php/cjhe/article/view/183312

Yong, D., Levy, R., \& Lape, N. (2015). Why no difference? A controlled flipped classroom study for an introductory differential equations course. PRIMUS, 25, 907-921. https://doi.org/10.1080/10511970.2015.1031307

Zack, L., Fuselier, J., Graham-Squire, A., Lamb, R., \& O'Hara, K. (2015). Flipping freshman mathematics. PRIMUS, 25(9-10), 803-813. https://doi.org/10.1080/10511970.2015.1031302

Zhang, N., \& Henderson, C. N. R. (2016). Brief, cooperative peer-instruction sessions during lectures enhance student recall and comprehension. Journal of Chiropractic Education, 30(2), 87-93. https://doi.org/10.7899/JCE-15-9 
Appendix A

Examples of $\mathrm{KCl}$ patterns

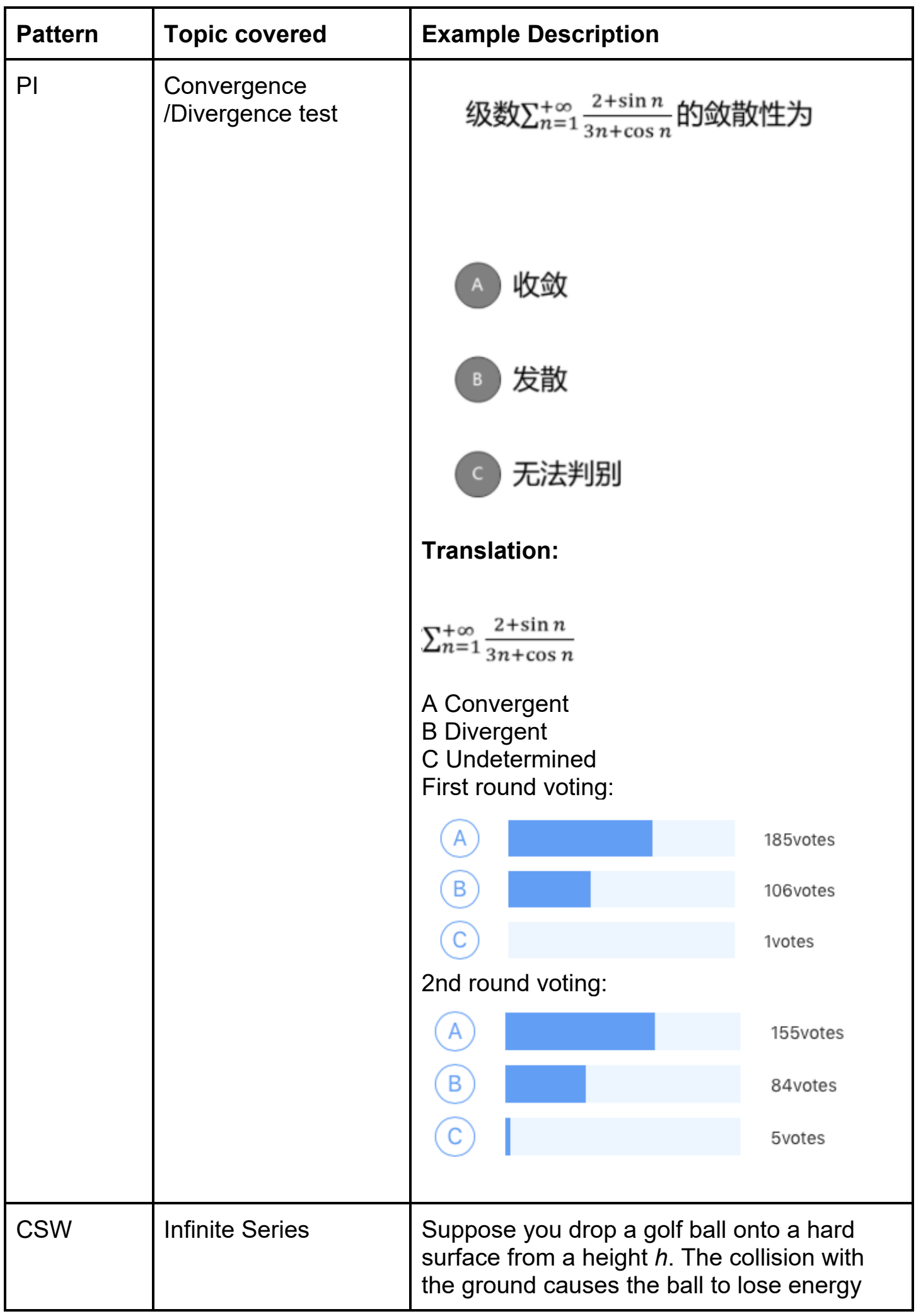




\begin{tabular}{|c|c|c|}
\hline Pattern & Topic covered & Example Description \\
\hline & & $\begin{array}{l}\text { and so it will not bounce back to its original } \\
\text { height. } \\
\text { The ball will then fall again to the ground, } \\
\text { bounce back up, and continue. Assume that } \\
\text { at each bounce the ball rises back to a } \\
\text { height } \frac{3}{4} \text { of the height from which it dropped. } \\
\text { Let } h_{n} \text { be the height of the ball on the } n \text {th } \\
\text { bounce, with } h_{0}=h \text {. In this exercise we will } \\
\text { determine the distance traveled by the ball } \\
\text { and the time it takes to travel that distance. } \\
\text { 1. For every individual: Determine a formula } \\
\text { for } h_{1}, h_{2} \text { and } h_{3} \text { in terms of } h \text {. } \\
\text { 2. Challenging part: Determine a formula } \\
\text { for } h_{n} \text { in terms of } h \text {. Write an infinite } \\
\text { series that represents the total distance } \\
\text { traveled by the ball. Then determine the } \\
\text { sum of this series and the total amount of } \\
\text { time the ball is in the air. }\end{array}$ \\
\hline CPC & $\begin{array}{l}\text { Tangent plane and } \\
\text { normal related } \\
\text { problems of space } \\
\text { surfaces }\end{array}$ & $\begin{array}{l}\text { 1. Teacher listed } 3 \text { topics for students to } \\
\text { work on to create clicker questions. } \\
\text { 2. All students vote for a best clicker } \\
\text { question within their own class. }\end{array}$ \\
\hline PPP & $\begin{array}{l}\text { Multivariate } \\
\text { differential geometry } \\
\text { application }\end{array}$ & $\begin{array}{l}\text { 1. Teacher shows the question } \\
z=f(x, y)=x^{2}+\cos (x y)+y z+x \\
\text { 2. Class } 8402 \text { solves the problem } f(0,1)=\text { ? } \\
\text { with real time comments } \\
\text { 3. Class } 8403 \text { solves the problem: on the } \\
\text { surface at point }(0,1, ?) \text {, find } z_{x} \mid(0,1, ?) \\
\text { 4. Class } 8404 \text { solves the problem: find } \\
z_{y} \mid(0,1, ?) \\
\text { 5. Class } 8407 \text { solves the problem: on the } \\
\text { surface, the normal vector to the tangent } \\
\text { plane is: } \vec{n}=(?, ?, ?) \\
\text { 6. Class } 8408 \text { solves the problem: the } \\
\text { equation of the tangent plane at point } \\
\text { (0,1,?) is: } \\
\text { 7. Class } 8409 \text { solves the problem: the } \\
\text { equation of the normal line at point } \\
\text { (0,1,?) is: }\end{array}$ \\
\hline
\end{tabular}




\section{Appendix B \\ Student Epistemology Survey Questions}

Personal relevance and learning preferences (Q1-Q7)

Learning from peers (Q8)

Teaching and sources of knowledge (Q9)

Student engagement (Q10)

1. On a scale of 1 to 5 , is what you learn in class relevant to your life outside of school? (1 being irrelevant, 5 being very relevant)

2. On a scale of 1 to 5 , do you have any influence over the topics you learn about in this class? ( 1 being no influence at all, 5 being a lot of influence)

3. On a scale of 1 to 5 , do you have any control over how you learn about them? (1 being no control at all, 5 being a lot of control)

4. On a scale of 1 to 5 , rank the following activities for learning new things based on your personal preference.

- Attending lectures

- Reading on my own

- Watching instructional videos

- Studying on my own

- Small group work

- Whole class discussions

- Working on projects

5. On a scale of 1 to 5 , rank who do you think is more responsible for your learning in the class.

- The teacher.

- Yourself.

- Your peers.

6. On a scale of 1 to 5 , rank the following options when you have questions.

- Prefer to ask teachers face-to-face.

- Prefer to ask my peers face-to-face.

- Prefer to search the answer by myself online.

7. On a scale of 1 to 5 , rank the following indicators when you know you have really learned something.

- Get a high score on an exam.

- Can apply the learning to a new problem or topic.

- Can explain it to a friend, to help them learn.

- Can solve problems using this knowledge.

8. On a scale of 1-5, rank the following statement:

- Working collaboratively with my peers helps me learn topics more deeply.

- Sharing information with my peers can help me in class.

- When peers share information with each other, the total group knowledge is greater than the knowledge of any one individual.

- Peers who pool their knowledge together are more innovative than individuals working independently. 
- The classroom community (all the students in class, considered together) is an important resource for my learning.

9. On a scale of $1-5$, rank the following statements.

9.1. How do you prefer to interact with the teacher?

- Listening to lecture about conceptual topics.

- Meeting one-on-one.

- Meeting the teacher with small group peers.

9.2. Are students' ideas (your own and those of your peers) important for learning in class?

9.3. The teacher in this class helps me feel better about myself as a mathematics learner.

9.4. Our homework should be important to help determine what happens during class time.

9.5. What are the important sources of knowledge in this class?

- Textbook.

- Internet materials.

- Lectures.

- TAs.

- My peers.

- Figuring things out myself

9.6. I like the teacher to teach my mathematics class through:

- Giving lectures of mathematical concepts and ideas.

- Showing how an equation is solved.

- Helping me work with a small group in problem solving.

- Showing how a real world problem is converted to a mathematical model.

- Engaging me in activities that solving a mathematical problem

10. The following activities matter to me in order for me to be engaged:

- Participating actively in small group discussions.

- Asking questions when I don't understand the instructor.

- Having fun in class.

- Helping fellow students.

- Finding ways to make the course material relevant to my life. 